\title{
Investigation of a Middle School Preservice Teacher's Knowledge of Content and Students
}

\section{Ebru Ersari (i) 1,*}

${ }^{1}$ Balıkesir University, Necatibey Faculty of Education, Department of Mathematics Education, Balıkesir, Turkey

\section{ARTICLE HISTORY}

Received: June 01, 2021

Revised: Aug. 09, 2021

Accepted: Sep. 24, 2021

Keywords:

Mathematical Knowledge

for Teaching,

Knowledge of Content and Students,

Preservice teacher education.

\begin{abstract}
The purpose of this study was to explicate one preservice middle grades mathematics teacher's Knowledge of Content and Students (KCS) in the context of multiple solution strategies. This study's purpose is to underline the importance of preservice teachers' KCS and provide possible investigative methods for evaluating preservice teachers' KCS. Specifically, the research inquiry guiding this study focused on how a middle school preservice mathematics teacher displays KCS when engaging with tasks about pattern recognition and linear functions in the context of multiple solution strategies. The data consisted of three videotaped semistructured interviews with the preservice mathematics teacher as well as the written work she produced during the interviews. This study explicated one preservice mathematic teacher's performance regarding two important themes of KCS: generating multiple possible solution strategies of middle school students and explaining multiple student solution strategies. In terms of generating multiple solution strategies of middle school students, the study found that the preservice mathematics teacher provided the same solution strategies that she employed when she solved the problems by herself. Regarding explaining multiple student solution strategies, this study revealed that the preservice teacher did not explicate how typical middle school students reason. The preservice teacher had limitations when explaining the possible procedures that students might have used to solve problems when given the final student solutions. With regard to the teacher's abilities to recognise and understand students' typical understandings and misunderstandings, the study demonstrated that the preservice teacher was capable of explaining some solution strategies but not all of them.
\end{abstract}

\section{INTRODUCTION}

In the teacher knowledge literature, Shulman's $(1986,1987)$ categorization is deemed seminal. Shulman (1986) initially organized teacher knowledge into three categories: subject matter content knowledge, pedagogical content knowledge, and curricular knowledge. Pedagogical content knowledge includes the consideration of teaching the content to students and how the content makes sense from the perspective of the students. Moreover, it consists of the knowledge of how teaching one way might have potential pitfalls or advantages regarding students' perspectives and backgrounds. Shulman proposed that pedagogical content knowledge makes a content specialist different from a pedagogue. Drawing on this categorization in his 1986 essay, Shulman (1987) reframed the categorization of knowledge

\footnotetext{
*CONTACT: Ebru ERSARI $\bigotimes$ ebru.ersari@balikesir.edu.tr $\equiv$ Balıkesir University, Necatibey Faculty of Education, Department of Mathematics Education, Balıkesir, Turkey
} 
and identified the seven categories of teacher knowledge as content knowledge, general pedagogical knowledge, curriculum knowledge, pedagogical content knowledge, knowledge of learners and their characteristics, knowledge of educational contexts, and knowledge of educational philosophies. Content knowledge, pedagogical knowledge, and curriculum knowledge are content-specific dimensions of teacher knowledge, whereas the other remaining categories are general dimensions of teacher knowledge and were not the primary focus of Shulman's work (Ball et al., 2008).

Taking Shulman's categorization of teacher knowledge, Ball et al. (2008) developed a model to explore the domains of Mathematical Knowledge for Teaching (MKT). They defined MKT as the "mathematical knowledge needed to carry out the work of teaching mathematics" (p. 395). According to Ball and her colleagues, MKT consists of two categories: Subject Matter Knowledge and Pedagogical Content Knowledge. Subject Matter Knowledge houses three subdomains: Common Content Knowledge (CCK), Knowledge at the Mathematical Horizon, and Specialized Content Knowledge (SCK). Pedagogical Content Knowledge consists of three subdomains: Knowledge of Content and Students (KCS), Knowledge of Content and Teaching (KCT), and Knowledge of Content and Curriculum.

According to Ball et al. (2008), the term Pedagogical Content Knowledge is used differently by various authors and has not been explored in depth. KCS, one component of Pedagogical Content Knowledge, is the combination of both the individual's knowledge of content and the individual's knowledge of students. Ball et al. (2008) explained KCS with "the example of analyzing a student error...[A] teacher might figure it out because she has seen students do this before with this particular type of problem" (p. 403). Teachers' familiarity with and knowledge of possible ways students think about the content is emphasized. The prior emphasis is on teachers' knowledge of students' thinking rather than their knowledge of content by itself. KCS focuses on teachers' knowledge about students' reasoning, how students understand the content, and what types of misconceptions students may have.

Studying KCS, one vital component of MKT, can reveal more accurate descriptions and measures of teachers' KCS, creating clearer distinction between different domains of MKT. This study aims to explore and underline why it is important to better understand preservice teachers' KCS. Preservice teachers need to be more familiar with possible student thinking before they actually begin teaching. In particular, in this study, I examined one preservice middle grades teacher's KCS in the context of three tasks involving linear functions.

\subsection{Literature Review}

Teaching mathematics is complicated (Boerst et al., 2011; Diez, 2010; Spalding et al., 2011), and teachers need to be responsive to students' mathematical reasoning when they teach (Dyer \& Sherin, 2016; Jacobs \& Empson, 2016; Thomas et al., 2017). However, studies pointed out that teachers cannot possibly give adequate explanations for every action each student takes when solving a mathematical problem (Nagle et al., 2017; Shin, 2020; Styers et al., 2020). This inability to predict or explain every action taken by a student exists regardless of whether the teacher is preservice (Nathan \& Petrosino, 2002; Van Dooren et al., 2002) or experienced (Asquith et al., 2007; Gvozdic \& Sadler, 2018). Nevertheless, research shows that teachers who have been trained to work through students' reasoning will be better prepared to notice trends in students' errors (Lee, 2021; Wuttke \& Seifried, 2017). Even though teaching multiple ways of solving problems can be challenging for preservice teachers, using multiple solving stretegies can have an impact on both high and low achieving preservice teachers by improving their problem solving skills (Gubermen \& Leikin, 2013). Using multiple strategies will in turn reproduce both the standard solution method in the course and new solution methods (Leikin \& Levav-Waynberg, 2008). Further, using multiple solutions have the potential to impact teacher knowledge. Mathematical Knowledge for Teaching (Ball et al., 2008), one of the 
important categorization of teacher knowledge, is an important component of effective mathematics teaching (Bryan et al., 2007). However, researchers have examined MKT differently. Some scholars focused on teachers' overall MKT (Charalambous, 2010; Jacob et al., 2017; Steele \& Rogers, 2012), others focused on a specific domain of MKT (Alqahtani \& Powell, 2017; Bansilal et al., 2014; Johnson \& Larsen, 2012), and others focused on more than one domain of MKT in their examinations (Hill, 2010; Lee et al., 2018; Ni Shuilleabhain, 2016). Ball et al. (2008) distinguished KCS from the other domains of MKT as follows:

consider what is involved in selecting a numerical example to investigate students' understanding of decimal numbers. The shifts that occur across the four domains, for example, ordering a list of decimals (CCK), generating a list to be ordered that would reveal key mathematical issues (SCK), recognizing which decimals would cause students the most difficulty (KCS), and deciding what to do about their difficulties (KCT), are important yet subtle. (p. 404)

KCS will both inform teachers' lessons and instructional methods to preempt students reasoning errors before they become ingrained patterns (Johnson \& Larsen, 2012). The ability to understand the nature of students' reasoning errors should be an aspirational goal and core component of teaching. KCS will increase the effectiveness of teacher instruction by helping students understand the mathematical principles and their errors in applying those principles to mathematical problems (Lannin et al., 2007). Different ways of explaining concepts can help different students conceptualize ideas (An et al., 2004). When students were prompted to use multiple solutions, they became more interested in mathematics. This new interest in turn led to greater student mathematical competencies (Schukajlow \& Krug, 2014). Multiple teaching approaches are better than one (Guberman \& Leikin, 2013) because diverse lesson delivery methods and explanatory approaches should engage a larger number of students and allow them to process information to become better mathematical thinkers. This focus on developing an awareness of multiple ways of teaching mathematical content will in turn address a common teaching tendency, the teacher's reliance on their own personal reasoning strategies as the basis for their lessons (Peterson \& Treagust, 1995). Consequently, this study employs KCS because the processes preservice teachers employ in their own problem-solving emerge in their teaching, whereas established teachers employ problem-solving methods learned from exposure to actual student solutions. Studies focusing on teachers' knowledge on students' reasoning found that teachers with limited knowledge lack the ability to listen actively to their students (Johnson \& Larsen, 2012), pose problems (Lee et al., 2018), interpret or answer students' responses and questions (Edelman, 2017), and predict students' reasoning (Asquith et al., 2007; Norton et al., 2011). One reason for their lack of knowledge can be the excessiveness of goals in teacher preparation programs that can exacerbate the tendency to omit multiple solution strategies in teachers' pedagogies (Hiebert \& Berk, 2020).

In terms of generating and explicating multiple solution strategies, Silver et al. (2005) found that teachers have cognitive (e.g., insecurity) and pedagogical (e.g., teaching difficulty) concerns regarding using multiple solution strategies. Interactive and reflective solutions can enhance teachers' understanding of students' multiple solution strategies (Leikin \& LevavWaynberg, 2007). Having a deeper understanding of both the content and students reasoning abilities are crucial aspects of those solution strategies (Taşdan \& Çelik, 2016). There should also be a clear focus on explaining mathematical concepts both procedurally and conceptually. Hiebert and Lefevre (1986) defined conceptual knowledge with an emphasis on relationships as: "a connected web of knowledge, a network in which the linking relationships are as prominent as the discrete pieces of information. Relationships pervade the individual facts and propositions so that all pieces of information are linked to some network" (pp. 3-4). They described procedural knowledge with an emphasis on its two kinds: "... a familiarity with the individual symbols of the system and with the syntactic conventions for acceptable 
configurations of symbols... [and] ... rules or procedures for solving mathematical problems" (p. 7). Conceptual and procedural knowledge constructs are generally referred to by mathematics educators as "qualities of knowledge" and by psyschologists as "thypes of knowledge" (Star, Stylianides, 2013, p. 15). Rittle-Johnson et al. (2015) claimed that there is a bidiractional relationship between conceptual and procedural knowledge that both types of knowledge supports each other.

Even though KCS is a vital component of teacher knowledge, there is scarce research investigating preservice mathematics teachers' KCS (Sitrava, 2020). One of the main reasons for this lack of critical data can be traced to the difficulty of writing KCS items. This difficulty is likely due to the fact that there is no common conceptual understanding and shared definition among researchers regarding what, exactly, KCS is (Hill et al., 2008). Another reason why there is limited research on this subject is because researchers' have great difficulty findings sample KCS items. With a greater sample of KCS items, researchers could have a better understanding of how to write new KCS items and utilize those items in their research. These sample items predominantly rely on the multiple-choice format. More items with open-ended questionaries or video interviews could aid resarchers in developing more diverse KCS items. Also, the difficulty involved in distinguishing between the MKT domains could be a contributing factor in the scarcity of data on the topic (Ball et al., 2008).

\subsection{Research Questions}

The purpose of this study was to scrutinize one preservice teacher's Knowledge of Content and Students (KCS) using pattern recognition and linear function tasks. To reach this objective, this study investigated the preservice teacher's knowledge on generating and explaining possible student thinking. Specifically, the research inquiry guiding this study focused on how a middle school preservice mathematics teacher displays KCS when engaging with tasks about pattern recognition and linear functions in the context of multiple solution strategies.

\section{METHODOLOGY}

\subsection{Participant}

The study reported in this article is a part of a broader study. The population of the broader study was middle grades preservice mathematics teachers studying at a southern university in the United States. Eight middle grades preservice mathematics teachers volunteered to participate in the study. Convenience sampling (Patton, 2002) was utilized, and four volunteers agreed to participate in the broader study. Selection was based on participants' schedule availability for the broader study rather than their levels of subject knowledge. Pseudonyms were used for each participant. In this study, the focus was one of the four volunteer middle school preservice teachers (Megan). Megan was selected because she was talkative, and her interviews provided the richest information in terms of preservice teachers' potential KCS limitations. Time and participant availability necessitated the study only focus on one preservice teacher. For a comparative study, the inservice and preservice teachers' KCS can be compared to strengthen the findings.

\subsection{Data Collection}

The data consisted of three videotaped semi-structured interviews (Maxwell, 1996) with Megan as well as the written work she produced during the interviews. Each interview took approximately one and a half hours; therefore, these interview data were supplemented by approximately 5 hours of videotaping, and all of them were transcribed.

Each of the three interviews were conducted around one mathematical task that was selected from the National Council of Teachers of Mathematics (NCTM) teaching and learning modules as part of an online toolkit aligned with the teaching practices contained in Principles to Actions 
(NCTM, 2014). All the tasks that were selected involved linear relationships. While this presents a limitation in that this study does not have evidence of the participant's KCS in other mathematics topic areas, it has more detailed information about her thinking regarding linear functions. The first interview focused on a Hexagon task. The visual representation of the Hexagon task can be accessed at https://www.nctm.org/Conferences-and-ProfessionalDevelopment/Principles-to-Actions-Toolkit/The-Case-of-Patrica-Rossman-and-the-HexagonTask/. In the Hexagon task, the preservice teacher was asked to find the patterns of the perimeters of trains constructed with regular hexagons. The first four trains, consisting of hexagonal wagons, were visually demonstrated in the problem. The first train consists of one, the second train of two, the third train of three, and the fourth train of four hexagonal wagons. Subsequent hexagons were added linearly to the right edge of the preceding hexagon. The first four trains consisting of hexagonal wagons were visually demonstrated in the problem as follows:

Figure 1. Visual depiction of the the Hexagon task.

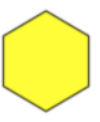

Train 1

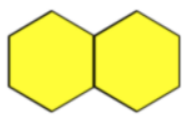

Train 2

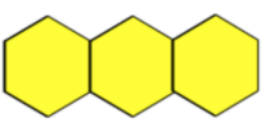

Train 3

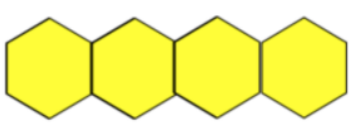

Train 4

The second interview focused on a Counting Cubes task. The visual representation of the Counting Cubes task can be accessed at https://www.nctm.org/Conferences-and-ProfessionalDevelopment/Principles-to-Actions-Toolkit/The-Case-of-Peter-Dubno-and-the-CountingCubes-Task/. In the Counting Cubes task, Megan was asked to elaborate on the patterns of several cubes. The cubes represent buildings consisting of five extensions. Each subsequent building adds an additional cube for each extension of the building. In the task, three buildings were represented visually. Building 1 consists of one cube only; building 2 consists of 5 extensions, an extension on each of the five faces of the cube in building 1; building 3 adds an additional cube in each direction. The first three buildings were shown in the problem as follows:

Figure 2. Visual depiction of the Counting Cubes task.
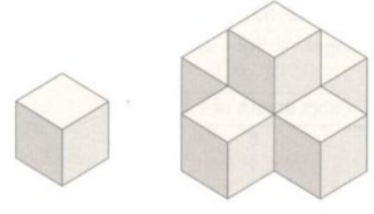

Building 1

Building 2

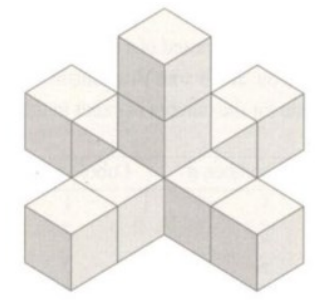

Building 3

The third interview focused on a Two Storage Tanks task. The visual representation of the Two Storage Tanks task can be accessed at https://www.nctm.org/Conferences-and-ProfessionalDevelopment/Principles-to-Actions-Toolkit/The-Case-of-Elizabeth-Brovey-and-the-Two-

Storage-Tanks-Task/. In the Two Storage Tanks task, Megan was asked to read a graph and find the amount of water in two storage tanks, one losing water and the other gaining water at different rates. The amount of water in both tanks over a period of time was demonstrated with the number of hours presented on the $x$ axis and gallons of water in the tank presented on the $y$ axis. The graph was provided in the problem as follows: 
Figure 3. Visual depiction of the Two Storage Tanks task.

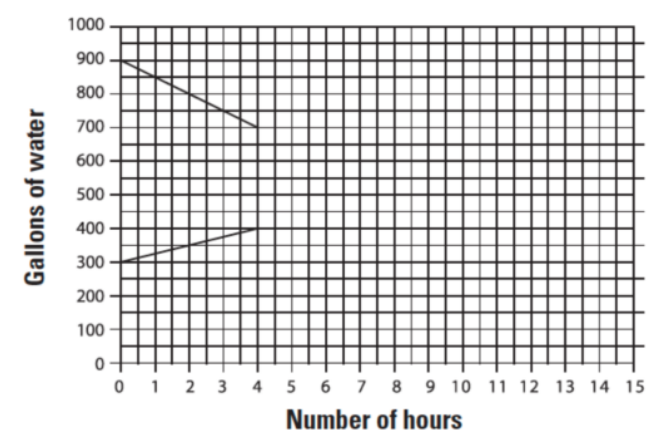

Specialized Content Knowledge (SCK) items developed by Hiebert et al.'s (2019) were modified for the interview protocol of this study, and their rubrics were adapted to evaluate the participant's KCS. Hiebert et al. (2019) specifically focused on three topics: multiplying twodigit whole numbers, subtracting fractions, and dividing fractions. This study focused on two topics: linear functions and pattern recognition. These sets of topics have transferrable qualities and shared concepts like integers, functions, and variables. Also, the relationship between quantities is the focus for both studies' topics; therefore, both studies are matching. The only widely known bank of KCS items is a set developed by Ball and colleagues, but those items are not available for public use. Although Hiebert et al.'s (2019) SCK items were developed for use with elementary school teachers (preservice and in-service), the basic structure of the items was transferrable to a middle grade context. Namely, this study drew heavily on Hiebert et al.'s (2019) SCK items and Ball et al.'s (2008) distinction of SCK and KCS for constructing KCS items and rubrics for this study. Hiebert et al.'s (2019) study used three-point rubrics 0 meaning no knowledge to 2 meaning extensive knowledge. This study also used three-point rubrics 0 referring to limited or lack of explanation; 1 referring to having some valid explanation but partial explanation; 2 having an adequate and elaborated explanation. Scoring rubrics are provided in the Appendix.

\subsection{Exploring KCS of the Preservice Teacher}

To compare and contrast the participant's KCS, her performance on tasks requiring her to 1) generate multiple solution strategies and 2) explain multiple solution strategies was evaluated. To generate multiple solution strategies, Megan was asked to generate three correct solution strategies she thought middle school students would likely use for each of the three tasks. In the generating multiple solution strategies part on the Hexagon task, the preservice teacher was asked to show and explain three different ways that students could correctly solve the perimeter of any train in the pattern; on the Counting Cubes task, three different ways that students could correctly find the number of cubes in the $\mathrm{n}^{\text {th }}$ building: on the Two Storage Tanks task, three different ways that students could correctly find the time at which the two tanks contain the same amount of water.

The Generating Multiple Solution Strategies part was used for exploring the preservice teacher's KCS and required her to predict and anticipate the typical middle school students' solution strategies. To evaluate how accurately and elaborately the participant generated multiple solution strategies, her responses to the Generating Multiple Solution Strategies theme of all of the three tasks were invesigated. To determine how accurately and elaborately the participant explained multiple solution strategies, her responses to the Explaining Multiple Solution Strategies theme of the Hexagon and Counting Cubes tasks were focused. Students' complete work was not given on these two tasks and the preservice teacher was asked to anticipate students' work. The preservice teacher was given three hypothetical students' final answers without providing the answers' solutions. She was asked to explain the possible 
procedures that each hypothetical student might have come up with for each of the three solutions. On the two tasks, the focus was on students' reasoning or challenges while examining students' work. If the task did not include the steps of the solutions but required the preservice teacher to predict the steps, the task was regarded as exploring the participant's KCS. In other words, for the Hexagon and Counting Cubes tasks, the hypothetical student work consisted only of hypothetical students' responses and required the participant to anticipate possible solution strategies, which aligned with KCS. Rachel, Sam, and Jason are the hypothetical students whose responses were provided in the Hexagon task. David, Emily, and Mary are the hypothetical students whose responses were provided in the Counting Cubes task. In the Hexagon task, Rachel's response was given as $2 n+2 n+2$ or $2(2 n)+2$; Sam's response was given as $5+$ $4(n-2)+5$ or $4(n-2)+5+5$, or $4(n-2)+10$; and Jason's response was given as $6 n-$ $2(n-1)$ as the perimeter of any train in the pattern. In the Counting Cubes task, David's response was given as $n+4(n-1)$; Emily's response was given as $1+5(n-1)$, and Mary's response was given as $5 n+1$ as the number of cubes in the $n^{\text {th }}$ building. For the Two Storage Tanks task, the hypothetical students' work was already given, the preservice teacher was not required to predict student work, and asked to explain student work mathematically, which aligned with SCK and is not the focus of this study.

\section{RESULTS / FINDINGS}

In this section, the findings of the participant's KCS on the tasks were presented regarding both the Generating Multiple Solution Strategies and the Explaining Multiple Solution Strategies themes. First, the participant's performance on the Hexagon, Counting Cubes, and Two Storage Tanks tasks were presented in the context of the Generating Multiple Solution Strategies theme. Preservice teacher's performance patterns on the tasks regarding the Generating Multiple Solution Strategies theme were then presented. Next, the participant's performance patterns on the Hexagon and Counting Cubes tasks were presented in the context of the Explaining Multiple Solution Strategies theme. Finally, the preservice teacher's performance patterns on the tasks in the Explaining Multiple Solution Strategies theme were presented.

\subsection{Generating Multiple Solution Strategies Theme}

\subsubsection{Hexagon task}

Even though Megan was asked to explain three different ways that students could solve the perimeter of any train in the pattern, she provided only two possible student solution strategies. Megan considered the students' potential solutions to the Hexagon task as follows: 1) finding the perimeter of each hexagon first and then subtracting the shared sides and 2) finding the perimeter of a set of hexagons (i.e., grouping 2 trains as a set or grouping 4 trains as a set) and then excluding the number of shared sides between sets of hexagons. Following is her response regarding students' possible first strategy:

Figure 4. Megan's response regarding students' possible first strategy on the Hexagon task.

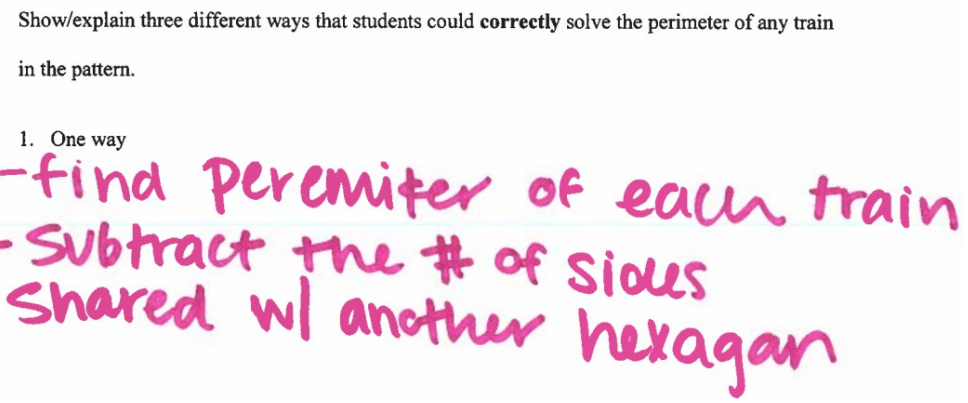


In the first strategy, the hexagons were considered separately, whereas in the second strategy, the hexagons were considered as a group. Following is her response regarding students' possible second strategy:

Figure 5. Megan's response regarding students' possible second strategy on the Hexagon task.

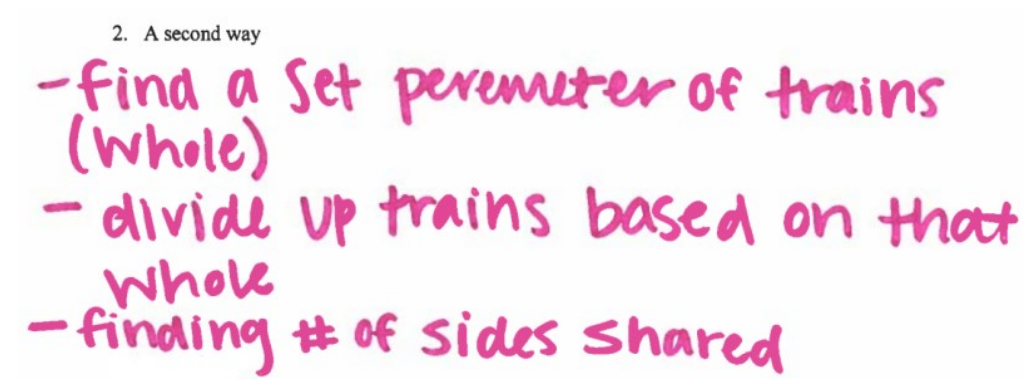

In her responses regarding students' possible strategies, Megan did not mention whether students could possibly find the relationship between the number of trains and the perimeter of hexagons in the task or not. In her own solution strategies, Megan grouped the hexagons by 2 hexagons in her third strategy and by 4 hexagons in her fourth strategy and then excluded the sides that were shared between the group of hexagons.

\subsubsection{Counting cubes task}

Even though Megan was asked to explain three different ways that students could solve the perimeter of any train in the pattern, similar to the Hexagon task, she provided only two possible student solution strategies. The following shows what Megan considered as students' possible solutions in the Counting Cubes task: 1) using the expression $5 n-4$ and 2) using the expression $5(n-1)+1$. Following is her explanation of students' possible first strategy:

Figure 6. Megan's explanation of students' possible first strategy on the Counting Cubes task.

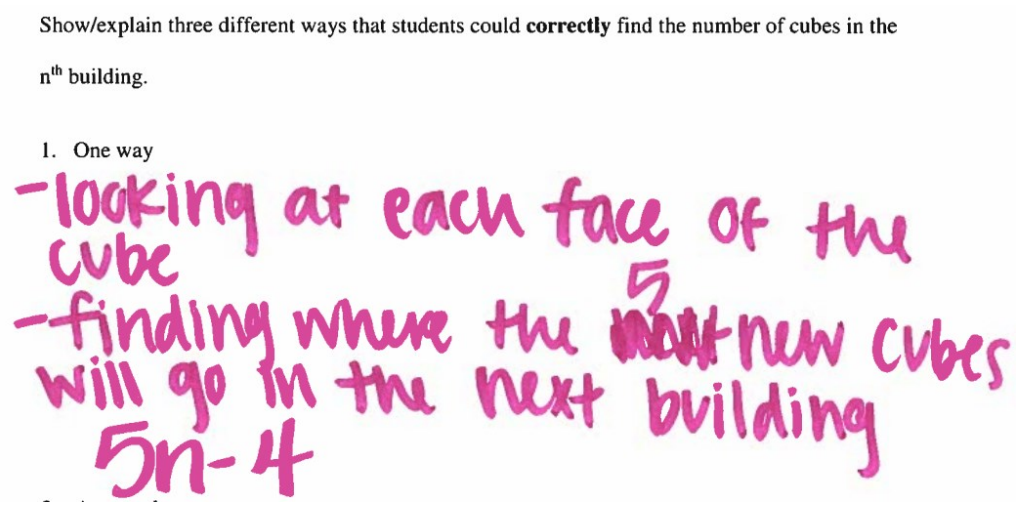

In terms of the first possible student strategy, Megan described the strategy as "looking at each face of the cube and finding where the 5 new cubes will go in the next building." The first student solution strategy that she came up with was the same as her first strategy. She was not clear what -4 represented when she described using expression $5 n-4$ in both of her own solution strategy and the students' possible solution strategies. She was incorrectly considering that each cube had 4 open faces and -4 represented those missing cubes that could come next to each of the open faces. She did not recognize that the last cubes in the extensions had 5 open faces as well as that -4 did not represent the cubes that could come next to the open faces. Her explanation of the second possible student solution strategy is as follows: 
Figure 7. Megan's explanation of students' possible second strategy on the Counting Cubes task.

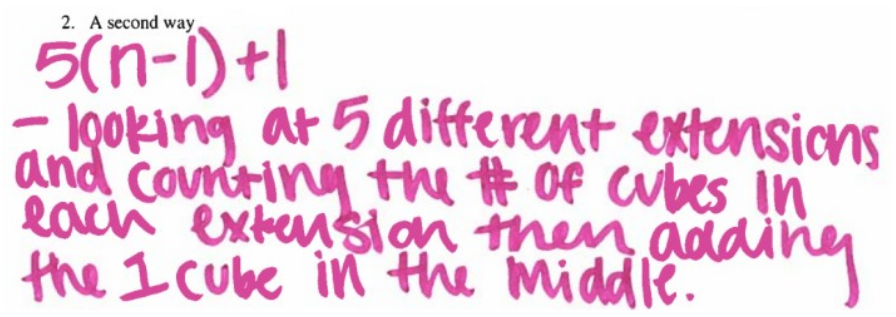

Megan described the second possible student strategy, using the expression $5(n-1)+1$, as "looking at 5 different extensions and counting the number of cubes in each extension then adding the 1 cube in the middle." This second student solution strategy was the same as her own second strategy, and Megan assumed that students would use the same methods she did.

\subsubsection{Two storage tanks task}

Different from the Hexagon and the Two Storage Tanks tasks, Megan provided three possible students' solutions to the Two Storage Tanks task as follows: 1) using $y=m x+b$ for finding the equations of both lines and finding the $y$ value for the same $x$ value by plugging in different $x$ values until finding the same $x$ and $y$ values and 2) using $y=m x+b$ for finding the equations of both lines, set them equal to each other, and find the intersection point, 3 ) extending the lines and finding the intersection point.

Her explanation of the first students' possible solution strategy is as follows:

Figure 8. Megan's explanation of students' possible first strategy on the Two Storage Tanks task.

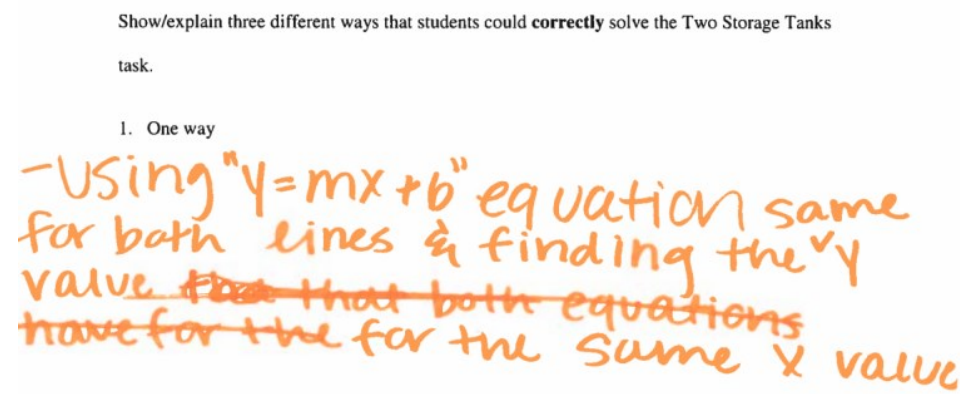

Megan thought using the equations $y=-50 x+900$ for tank T and $y=25 x+300$ for tank $\mathrm{W}$ and plugging in numbers until getting the same $x$ and $y$ value as the first solution strategy students would likely try. She, however, considered that this strategy was too hard to apply if the $x$ value was a big number.

Her explanation of the second possible student solution strategy is as follows:

Figure 9. Megan's work on students' possible second strategy on the Two Storage Tanks task.

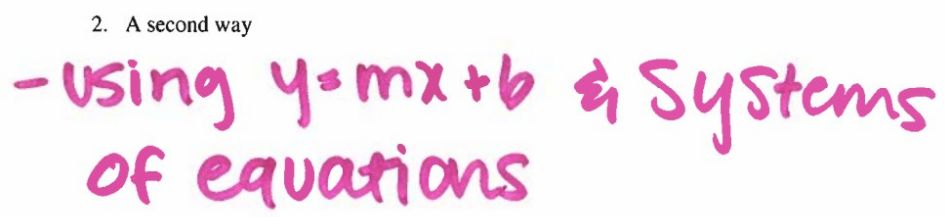

As a more systematic way to solve the problem, Megan explained the second solution strategy as finding the equations of each line using $y=m x+b$ and using systems of equations to find the $x$ and $y$ values for the intersection point.

Her explanation of the third possible student solution strategy is as follows: 
Figure 10. Megan's work on students' possible third strategy on the Two Storage Tanks task.

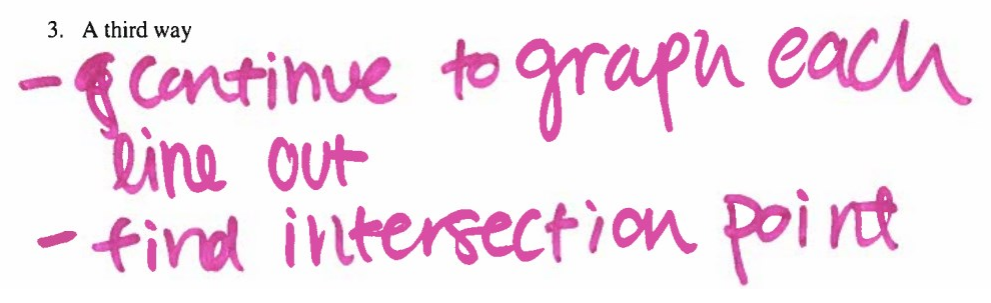

The third solution strategy Megan thought students might try was extending each graphed line until they meet then finding the intersection point.

\subsubsection{Patterns among the tasks regarding Generating Multiple Solution Strategies theme}

Megan provided correct expressions as possible student solutions. However, she could not explain what some numbers and variables referred to in the expressions that she provided. She also explained some of the meanings of the variables inaccurately. For instance, she related -4 with the open faces of the cubes even though -4 was not related with the number of open faces. Even though Megan grappled with explaining the meaning of -4 in the expression $5 n-4$, she still reported as one possible solution strategy. Her challenges when solving the tasks herself were similar to her challenges when explaining the possible student solutions. Also, Megan did not offer explanations about which solutions would be easier or more difficult for students.

Megan showed some possible student solution strategies, but her student solutions lacks variety for different levels of students. She provided similar strategies to the ones she came up with when solving the tasks herself. However, she could not relate the student solution strategies that she generated to middle school students' reasoning. She did not hypothesize which strategy might have been more common and which strategy might have been less common among middle school students and did not provide reasons. She explained procedurally what students might possibly have done; however, she did not explain conceptually what they might have done.

\subsection{Explaining Multiple Solution Strategies Theme}

\subsubsection{Hexagon task}

Megan first explained Jason's response because it was similar to her solution. Following is her explanation of Jason's response:

Figure 11. Megan's explanation of Jason's response.

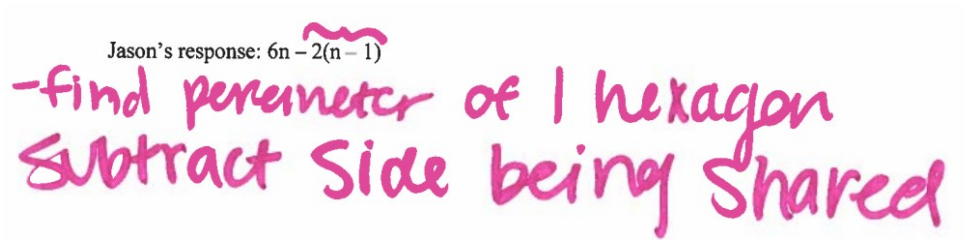

Megan described Jason's response, $6 n-2(n-1)$, as finding the perimeter of one hexagon and subtracting $2(n-1)$, which represented the number of sides being shared. Next, Megan explained Sam's response. Megan did not write down any explanation; however, she underlined some parts of his work. Following shows Megan's work on Sam's response:

Figure 12. Megan's work on Sam's response.

Sam's response: $5+4(n-2)+5$, or $4(n-2)+5+5$, or $4(n-2)+10$ 
In Sam's response, $5+4(n-2)+5$, or $4(n-2)+5+5$, or $4(n-2)+10$, she stated that 5 was the number of sides in the first hexagon and the other 5 was the number of sides in the last hexagon; $4(n-2)$ was number of the sides in the middle hexagon, where 4 was the number of sides that were on the perimeter for each middle hexagon and $n-2$ was the number of hexagons in the middle.

Even though Rachel's response was written first among other possible solution strategies, Megan preferred to explain Rachel's response last.

Figure 13. Megan's work on Rachel's response.

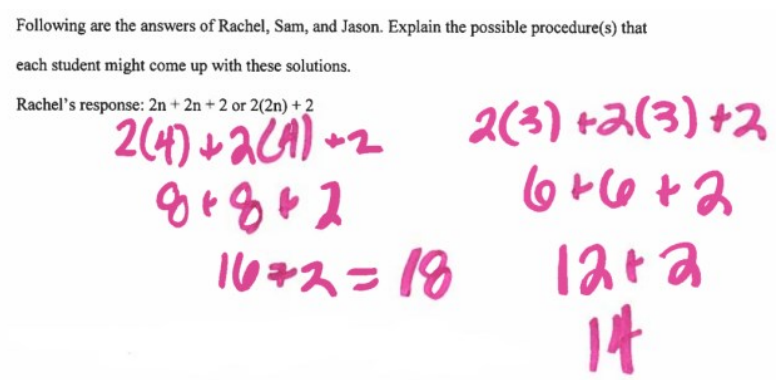

In Rachel's response, $2 n+2 n+2$ or $2(2 n)+2$, Megan struggled to explain what 2 s referred to in the expressions. She checked that Rachel's expression was correct by plugging in 3 and 4 for $n$ in the expression and finding the correct perimeters. She stated in terms of Rachel's response that, "My only thing that I think I can come up for her is that she is taking a hexagon and saying that is $2 n$. And so, then she is adding up $2 n+2 n$ and then 2 would be the sides in the middle." When she was asked what $2 n$ represented, she explained that "I know $n$ definitely represents the number of trains, and then this is just another way of showing this part of the equation of subtracting the sides out [showing $-2(n-1)$ in Jason's response]." Because Megan said that $-2(n-1)$ was the number of shared sides when she was explaining Jason's response, she was asked if $2 n$ in Rachel's response represented the shared sides. She explained that, "No, I think she is representing that in a different way, but it is very similar to the $2 n$ down here, but it is represented in a different way, to me, not as clear as Jason's responses." She asserted that none of the $2 \mathrm{~s}$ in Rachel's explanation was clear, and Rachel needed more explanation regarding what those numbers referred to. Ultimately, Megan was still struggling to explain what the numbers in Rachel's representation referred to.

\subsubsection{Counting cubes task}

Because Emily's response $1+5(n-1)$ was similar to her own response, Megan first started explaining Emily's solution by describing 1 as the 1 cube in the middle, 5 as the number of extensions, and $n-1$ as the number of cubes in each extension. Following is Megan's work on Emily's response:

Figure 14. Megan's work on Emily's response.

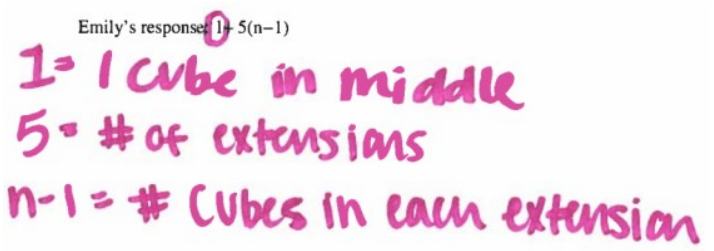

Then, Megan described Mary's response, $5 n+1$, describing 1 as the cube in the middle. Following is Megan's comments on Mary's response: 
Figure 15. Megan's work on Mary's response.

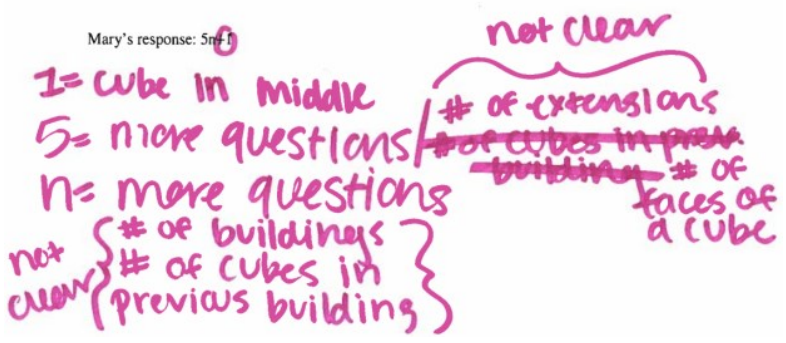

Megan asserted that the meaning of 5 and $n$ was not clear in Mary's expression because 5 could be either the number of extensions or the number of faces of a cube and $n$ could be either the number of buildings or the number of cubes in the previous building. She did not recognize that $n$ could be the number of cubes in each extension excluding the middle cube and +1 was the cube in the middle. Her description of what 5 and $n$ could mean again shows that she conflated the number of cubes in a building with the number of open faces in a cube. Megan's lack of knowledge on the task impacted her incorrect assumptions about Mary's response.

In terms of David's response $n+4(n-1)$, Megan thought that 4 was the number of open faces of a cube; $(n-1)$ was the number of cubes in each extension. Following is Megan's comments on David's response:

Figure 16. Megan's work on David's response.

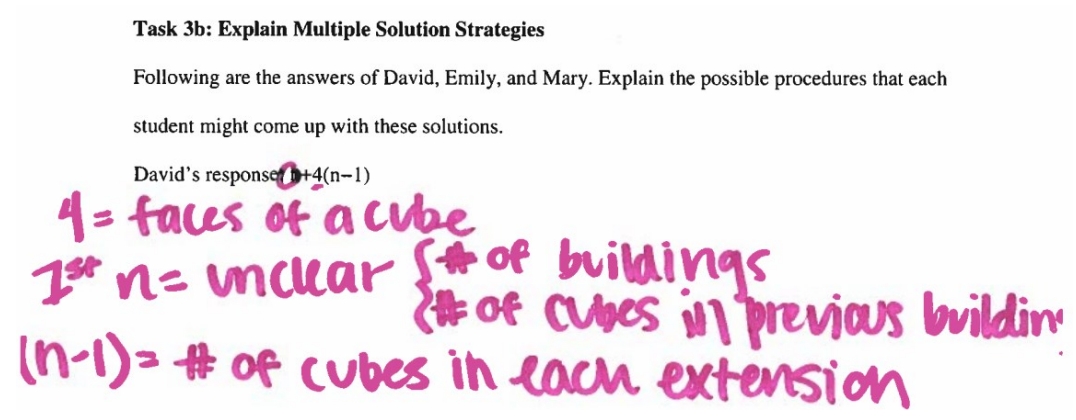

She said the meaning of the first $n$ was not clear and could refer to either the number of buildings or the number of cubes in the previous building. As Megan counted the number of faces of a cube in her own solution, she could relate David's response with her own solution. Ultimately, Megan struggled to explain the meaning of the numbers in both David's and Mary's responses.

\subsubsection{Patterns among the tasks regarding explaining multiple solution strategies theme}

Megan preferred to explain the solutions that she was familiar with first and the solutions that she struggled with the most last. Megan struggled to explain some of the students' solution strategies. For instance, Megan failed to explain what the $2 \mathrm{~s}$ referred to in the expression $2 n+$ $2 n+1$ or $2(2 n)+2$ in the Hexagon task. Megan sometimes represented the variables in student solutions inaccurately. For instance, she thought that 4 in the expression $n+4(n-1)$ in the Counting Cubes task represented the number of faces of a cube. However, 4 in the expression $n+4(n-1)$ represented the number of extensions.

Megan provided explanations of some of the student solution strategies. However, she had limited conceptual understanding of the solution strategies. She preferred to start explaining students' solutions based on the ones that were similar to her own strategy. 


\section{DISCUSSION and CONCLUSION}

In the teacher knowledge literature, Shulman's $(1986,1987)$ categorization of teacher knowledge is prominent. Shulman's seven categoris provide the basis for numerous explanations of teacher knowledge. Developing Shulman's influential teacher knowledge categorization, Ball et al. (2008) constructed MKT. KCS, one of the domains of MKT, plays an important role in shedding light on teachers' knowledge. In spite of the scarcity of research on KCS, studies have shown that teachers lack KCS (Edelman, 2017; Johnson \& Larsen, 2012; Lee et al., 2018). The purpose of this study is to underline the importance of the investigation of preservice teachers' KCS. Specifically, this research focused on a middle school preservice teachers' KCS when engaging with tasks about pattern recognition and linear functions in the context of multiple solution strategies. Generating multiple solution strategies and explaining multiple solution strategies are the two themes this study uses to explore the preservice teacher's KCS.

In terms of predicting students' thinking and confusion, the preservice teacher, Megan, provided the same solution strategies that she provided when she solved the problems by herself. This study shows that the preservice teacher's performance on predicting students' reasoning might depend on her own knowledge. In general, Megan's student predictions mirrored her own solutions to the tasks. Similar to this study, Norton et al. (2011) found that there can be a relationship between prospective elementary teachers' prediction of students' work and their own mathematical knowledge. Regarding the acquaintance with students' mathematical reasoning, Megan did not explicate how typical middle school students reason. This finding is consistent with Asquith et al.'s (2007) finding that teachers have difficulties predicting students' understanding and reasoning. In Asquith et al.'s (2007) study, middle school teachers struggled to predict students' understanding of the equal sign and variable, whereas in this study, the preservice teacher had difficulties predicting middle school students' possible reasoning about pattern recognition and linear functions. With regard to students' typical understandings and misunderstandings, Megan was able to explain some solution strategies, but she could not explain others. For instance, Megan struggled to explain how the student produced the expression $2 n+2 n+2$ or $2(2 n)+2$ for finding the perimeter of the hexagons in the Hexagon task. Megan stated that she did not know where any of the $2 \mathrm{~s}$ come from in the expression $2 n+2 n+2$ or $2(2 n)+2$. She could not explain that in this strategy, the student considers the tops of the hexagons as two times the train number and the bottoms. Also, Megan could not describe that since there are two sides on top of each hexagon, the number of top sides on any train is $n \times 2$ ( $n$ hexagons $\times 2$ top sides per hexagon) or $2 n$. Similarly, she did not explain that the number of bottom sides is also $2 n$ in the student's solution.

Regarding multiple solution strategies, Silver et al. (2015) showed that veteran middle grades mathematics teachers were also concerned about explaining multiple solution strategies to their students. Those veteran teachers stated that some students might have had difficulties understanding different ways of solving problems. Therefore, multiple solution strategies can be challenging for teachers in terms of their ability to solve problems in multiple ways by themselves, as well as their ability to explain multiple solutions to students with limited understanding. Similar to this study, the teacher in the study of Johnson \& Larsen (2012) had constraints on understanding her students' struggles. Different from this study, the participant in Johnson \& Larsen's study (2012) had higher content knowledge. In their study, the teacher was a mathematician and got his PhD in mathematics. Therefore, this study and Johnson \& Larsen's (2012) study showed that teachers might struggle to understand from students' perspectives no matter how knowledgeable they are in terms of the content. In the Counting Cubes task example, Megan was able to explicate some solution strategies, but she could not explain some other solution strategies and provided inaccurate explanations regarding what the 
variables could represent. For instance, when she explained the expression $5 n+1$ in the Counting Cubes task, she said that 5 could be either the number of extensions or the number of faces of a cube. However, 5 did not represent the number of faces of a cube in the expression. When Megan explained the expression $n+4(n-1)$, she thought that 4 was the number of faces on a cube and that the first $n$ could be either the number of buildings or the number of cubes in the previous building. However, neither 4 represented the number of faces of a cube, nor did $n$ represent the number of buildings.

In sum, this study explicated one preservice teacher's performance regarding two important themes of KCS: generating multiple solution strategies and explaining multiple solution strategies. More research is needed to construct KCS items to elaborate more on what constitutes teachers' KCS. Also, teachers' performance on the components of KCS requires more investigation. In this study, no professional development or interventions were employed. Thus, the impact of professional development on KCS can be explored. More research is needed to understand how to improve teachers' KCS. Additionally, preservice teachers' KCS can be explored further for different content and different grade levels with more participants by using more tasks. Also, the relationship between other domains of teacher knowledge can be investigated. How KCS impacts preservice and in-service teachers' teaching strategies could be examined. In order to improve the quality of teacher education programs, future studies can explore the relationship between preservice teachers' knowledge and their teaching strategies. Also, researchers need to conduct studies using well-designed KCS tasks. For this purpose, they can collaborate together to develop KCS tasks for their future studies and produce KCS items that are publicly available.

\section{Acknowledgements}

This study is based on the dissertation study conducted by the author. I want to thank my advisor Dr. Denise Spangler and my committee members Dr. Anna Conner and Dr. Steve Oliver for their guidance. I also would like to thank Dr. Andrew Izsák for his feedback. I owe special thanks to the participant, Megan, who accepted to be part of this study. Additionally, I want to thank the Ministry of National Education of the Republic of Turkey for supporting me financially during my study in the United States.

\section{Declaration of Conflicting Interests and Ethics}

The author declares no conflict of interest. All scientific responsibility of the manuscript belongs to the author. Institutional Review Board reviewed and approved that the study is aligned with research publication ethics (IRB ID: STUDY00006215, Approval Date: 21/06/2018).

\section{ORCID}

\section{Ebru ERSARI (iD https://orcid.org/0000-0002-0324-3185}

\section{REFERENCES}

Alqahtani, M. M., \& Powell, A. B. (2017). Mediational activities in a dynamic geometry environment and teachers' specialized content knowledge. The Journal of Mathematical Behavior, 48, 77-94.

An, S., Kulm, G., \& Wu, Z. (2004). The pedagogical content knowledge of middle school, mathematics teachers in China and the US. Journal of Mathematics Teacher Education, 7(2), 145-172.

Asquith, P., Stephens, A. C., Knuth, E. J., \& Alibali, M. W. (2007). Middle school mathematics teachers' knowledge of students' understanding of core algebraic concepts: Equal sign and variable. Mathematical Thinking and Learning, 9(3), 249-272. 
Ball, D. L., Thames, M. H., \& Phelps, G. (2008). Content knowledge for teaching. Journal of Teacher Education, 59(5), 389-407.

Baki, A. (2020). Matematiği ögretme bilgisi (3rd ed.). PegemAkademi

Bansilal, S., Mkhwanazi, T., \& Brijlall, D. (2014). An exploration of the common content knowledge of high school mathematics teachers. Perspectives in Education, 32(1), 3450 .

Boerst, T. A., Sleep, L., Ball, D. L., \& Bass, H. (2011). Preparing teachers to lead mathematics discussions. Teachers College Record, 113(12), 2844-2877.

Bryan, C. A., Wang, T., Perry, B., Wong, N., \& Cai, J. (2007). Comparison and contrast: Similarities and differences of teachers' views of effective mathematics teaching and learning from four regions. ZDM, 39(4), 329-340.

Charalambous, C. (2010). Mathematical knowledge for teaching and task unfolding: An exploratory study. The Elementary School Journal, 110(3), 247-278.

Diez, M. E. (2010). It is complicated: Unpacking the flow of teacher education's impact on student learning. Journal of Teacher Education, 61(5), 441-450.

Dyer, E. B., \& Sherin, M. G. (2016). Instructional reasoning about interpretations of student thinking that supports responsive teaching in secondary mathematics. $Z D M, 48(1-2), 69-$ 82.

Edelman, J. (2017). How preservice teachers use children's literature to teach mathematical concepts: focus on mathematical knowledge for teaching. International Electronic Journal of Elementary Education, 9(4), 741-752.

Guberman, R., \& Leikin, R. (2013). Interesting and difficult mathematical problems: changing teachers' views by employing multiple-solution tasks. Journal of Mathematics Teacher Education, 16(1), 33-56.

Gvozdic, K., \& Sander, E. (2018). When intuitive conceptions overshadow pedagogical content knowledge: Teachers' conceptions of students' arithmetic word problem solving strategies. Educational Studies in Mathematics, 98(2), 157-175.

Hiebert, J., \& Berk, D. (2020). Foreword: Building a profession of mathematics teacher education. The Mathematics Enthusiast, 17(2), 325-336.

Hiebert, J., Berk, D., Miller, E., Gallivan, H., \& Meikle, E. (2019). Relationships between opportunity to learn mathematics in teacher preparation and graduates' knowledge for teaching mathematics. Journal for Research in Mathematics Education, 50(1), 23-50.

Hiebert, J., \& Lefevre, P. (1986). Conceptual and procedural knowledge in mathematics: An introductory analysis. In J. Hiebert (Ed.), Conceptual and procedural knowledge: The case of mathematics (pp. 1-27). Lawrence Erlbaum Associates.

Hill, H. C. (2010). The nature and predictors of elementary teachers' mathematical knowledge for teaching. Journal for Research in Mathematics Education, 41(5), 513-545.

Hill, H. C., Ball, D. L., \& Schilling, S. G. (2008). Unpacking pedagogical content knowledge: Conceptualizing and measuring teachers' topic-specific knowledge of students. Journal for Research in Mathematics Education, 39(4), 372-400.

Jacob, R., Hill, H., \& Corey, D. (2017). The impact of a professional development program on teachers' mathematical knowledge for teaching, instruction, and student achievement. Journal of Research on Educational Effectiveness, 10(2), 379-407.

Jacobs, V. R., \& Empson, S. B. (2016). Responding to children's mathematical thinking in the moment: An emerging framework of teaching moves. ZDM Mathematics Education, 48(1-2), 185-197.

Johnson, E., \& Larsen, S. P. (2012). Teacher listening: The role of knowledge of content and students. The Journal of Mathematical Behavior, 31(1), 117-129.

Lannin, J. K., Barker, D. D., \& Townsend, B. E. (2007). How students view the general nature of their errors. Educational Studies in Mathematics, 66(1), 43-59. 
Lee, M. Y. (2021). Using a technology tool to help pre-service teachers notice students' reasoning and errors on a mathematics problem. ZDM, 53(1), 135-149.

Lee, Y., Capraro, R. M., \& Capraro, M. M. (2018). Mathematics teachers' subject matter knowledge and pedagogical content knowledge in problem posing. International Electronic Journal of Mathematics Education, 13(2), 75-90.

Leikin, R., \& Levav-Waynberg, A. (2007). Exploring mathematics teacher knowledge to explain the gap between theory-based recommendations and school practice in the use of connecting tasks. Educational Studies in Mathematics, 66(3), 349-371.

Leikin, R., \& Levav-Waynberg, A. (2008). Solution spaces of multiple-solution connecting tasks as a mirror of the development of mathematics teachers' knowledge. Canadian Journal of Science, Mathematics and Technology Education, 8(3), 233-251.

Maxwell, J. A. (1996) Qualitative research design: An interactive approach. Sage Publications.

Nagle, C., Moore-Russo, D., \& Styers, J. (2017) Teachers' interpretations of student statements about slope. In E. Galindo, \& J. Newton (Eds.), Proceedings of the 39th annual meeting of the North American Chapter of the International Group for the Psychology of Mathematics Education, (pp. 589-596).

Nathan, M. J., \& Petrosino, A. (2003). Expert blind spot among preservice teachers. American Educational Research Journal, 40(4), 905-928.

National Council of Teachers of Mathematics. (2014). Principles to actions: Ensuring mathematical success for all. NCTM.

National Council of Teachers of Mathematics Principles to Actions Professional Learning Toolkit. https://www.nctm.org/PtAToolkit/

Ni Shuilleabhain, A. (2016). Developing mathematics teachers' pedagogical content knowledge in lesson study. International Journal for Lesson and Learning Studies, 5(3), 212-226.

Norton, A., McCloskey, A., \& Hudson, R. A. (2011). Prediction assessments: Using videobased predictions to assess prospective teachers' knowledge of students' mathematical thinking. Journal of Mathematics Teacher Education, 14(4), 305-325.

Patton, M. Q. (2002). Qualitative research and evaluation methods. (3rd ed.). SAGE.

Peterson, R., \& Treagust, D. (1995). Developing preservice teachers' pedagogical reasoning ability. Research in Science Education, 25(3), 291-305.

Rittle-Johnson, B., Schneider, M., \& Star, J. R. (2015). Not a one-way street: Bidirectional relations between procedural and conceptual knowledge of mathematics. Educational Psychology Review, 27(4), 587-597.

Schukajlow, S., \& Krug, A. (2014). Do multiple solutions matter? Prompting multiple solutions, interest, competence, and autonomy. Journal for Research in Mathematics Education, 45(4), 497-533.

Shin, D. (2020). Preservice Mathematics Teachers' Selective Attention and Professional Knowledge-Based Reasoning About Students' Statistical Thinking. International Journal of Science and Mathematics Education, https://doi.org/10.1007/s10763-02010101-W

Shulman, L. S. (1986). Those who understand: Knowledge growth in teaching. Educational Researcher, 15(2), 4-14.

Shulman, L. S. (1987). Knowledge and teaching: Foundations of the new reform. Harvard Educational Review, 57(1), 1-22.

Silver, E. A., Ghousseini, H., Gosen, D., Charalambous, C., \& Strawhun, B. T. (2005). Moving from rhetoric to praxis: Issues faced by teachers in having students consider multiple solutions for problems in the mathematics classroom. The Journal of Mathematical Behavior, 24(3-4), 287-301. 
Sitrava, R. T., (2020). Middle School Mathematics Teachers' Reasoning about Students' Nonstandard Strategies: Division of Fractions. International Journal for Mathematics Teaching and Learning, 21(1), 77-93.

Spalding, E., Klecka, C. L., Lin, E., Wang, J., \& Odell, S. J. (2011). Learning to teach: It's complicated but it's not magic. Journal of Teacher Education, 62(1), 3-7.

Star, J. R., \& Stylianides, G. J. (2013). Procedural and conceptual knowledge: Exploring the gap between knowledge type and knowledge quality. Canadian Journal of Science, Mathematics and Technology Education, 13(2), 169-181.

Steele, M. D., \& Rogers, K. C. (2012). Relationships between mathematical knowledge for teaching and teaching practice: The case of proof. Journal of Mathematics Teacher Education, 15(2), 159-180.

Styers, J. L., Nagle, C. R., \& Moore-Russo, D. (2020). Teachers' noticing of students' slope statements: attending and interpreting. Canadian Journal of Science, Mathematics and Technology Education, 20(3), 504-520.

Taşdan, B. T., \& Çelik, A. (2016). A Conceptual Framework for Examining Mathematics Teachers' Pedagogical Content Knowledge in the Context of Supporting Mathematical Thinking. European Journal of Education Studies, 2(5), 90-120.

Thomas, J., Jong, C., Fisher, M. H., \& Schack, E. O. (2017). Noticing and knowledge: Exploring theoretical connections between professional noticing and mathematical knowledge for teaching. The Mathematics Educator, 26(2), 3-25.

Van Dooren, W., Verschaffel, L., \& Onghena, P. (2002). The impact of preservice teachers' content knowledge on their evaluation of students' strategies for solving arithmetic and algebra word problems. Journal for Research in Mathematics Education, 33(5), 319-351.

Wuttke, E., \& Seifried, J. (Eds.). (2017). Professional error competence of preservice teachers: Evaluation and support. Springer. 


\section{APPENDIX ${ }^{\dagger}$}

Scoring Rubric for the Hexagon task

\begin{tabular}{|c|c|c|}
\hline \multicolumn{3}{|c|}{ Task 2: Generate Multiple Solution Strategies } \\
\hline Topic & Valid Strategies & Description of Coding \\
\hline \multirow[t]{3}{*}{$\begin{array}{l}\text { Finding the } \\
\text { pattern in } \\
\text { the Hexagon } \\
\text { task }\end{array}$} & $\begin{array}{l}\text { Tops and bottoms } \\
\text { plus ends }\end{array}$ & $\begin{array}{l}\text { In this strategy, the student considers the tops of the } \\
\text { hexagons as two times the train number and the bottoms. } \\
\text { Since there are two sides on top of each hexagon, the number } \\
\text { of top sides on any train is } n \times 2 \text { ( } n \text { hexagons } \times \\
2 \text { top sides per hexagon) or } 2 n \text {. Similarly, the number of } \\
\text { bottom sides is also } 2 n \text {. Then, the two end sides are } \\
\text { considered separately. } \\
\text { Possible representations: Verbal description. Equations: } 2 n+ \\
2 n+2 \text { or } 2(2 n)+2 \text {. }\end{array}$ \\
\hline & $\begin{array}{l}\text { Tops and bottoms } \\
\text { of each plus ends }\end{array}$ & $\begin{array}{l}\text { In this strategy, the student considers the tops of each } \\
\text { hexagon and the bottoms of each hexagon. Then, the two end } \\
\text { sides are considered separately. } \\
\text { Possible representations: Verbal description. Equations: } \\
4 n+2 \text {, or }(2+2) n+2\end{array}$ \\
\hline & $\begin{array}{l}\text { Insides and } \\
\text { Outsides }\end{array}$ & $\begin{array}{l}\text { In this strategy, the student considers the end hexagons, } \\
\text { noticing that each contributes five to the perimeter. Then, } \\
\text { they consider that each internal hexagon contributes four. } \\
\text { Possible representations: Verbal description. Equations: } 5+ \\
4(n-2)+5 \text {, or } 4(n-2)+5+5 \text {, or } 4(n-2)+10 \text {. } \\
\text { The second train is the two end hexagons that will be } \\
\text { separated. They have } 5 \text { sides each (not including the one } \\
\text { shared in the middle). Thus, the perimeter is } 5+5 \text { or } 10 \text {. }\end{array}$ \\
\hline
\end{tabular}

${ }^{\dagger}$ All the scoring rubrics are made based on the task solution paths on NCTM's Professional Learning Toolkit 


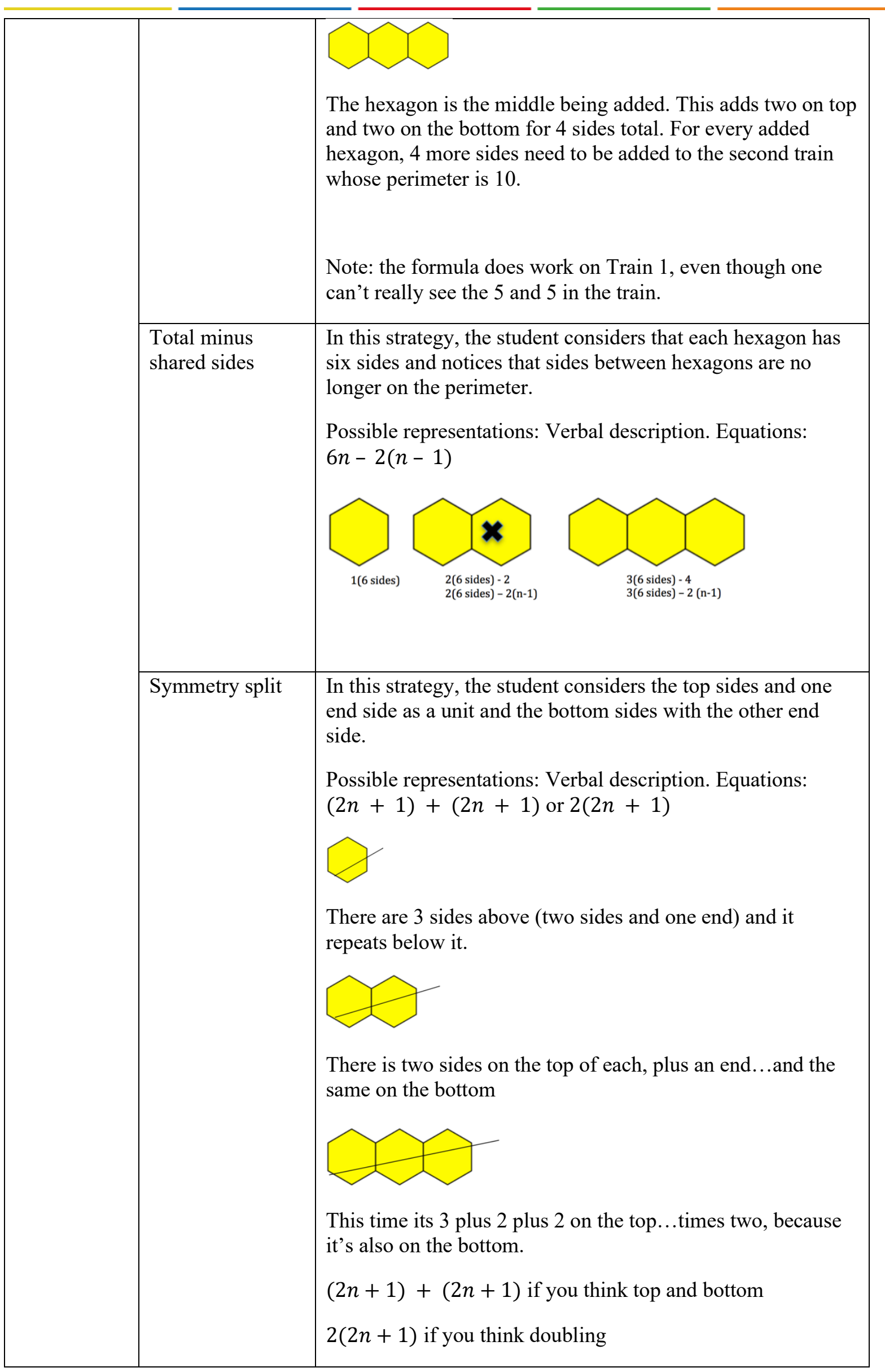




\begin{tabular}{|c|c|}
\hline Increases by four & 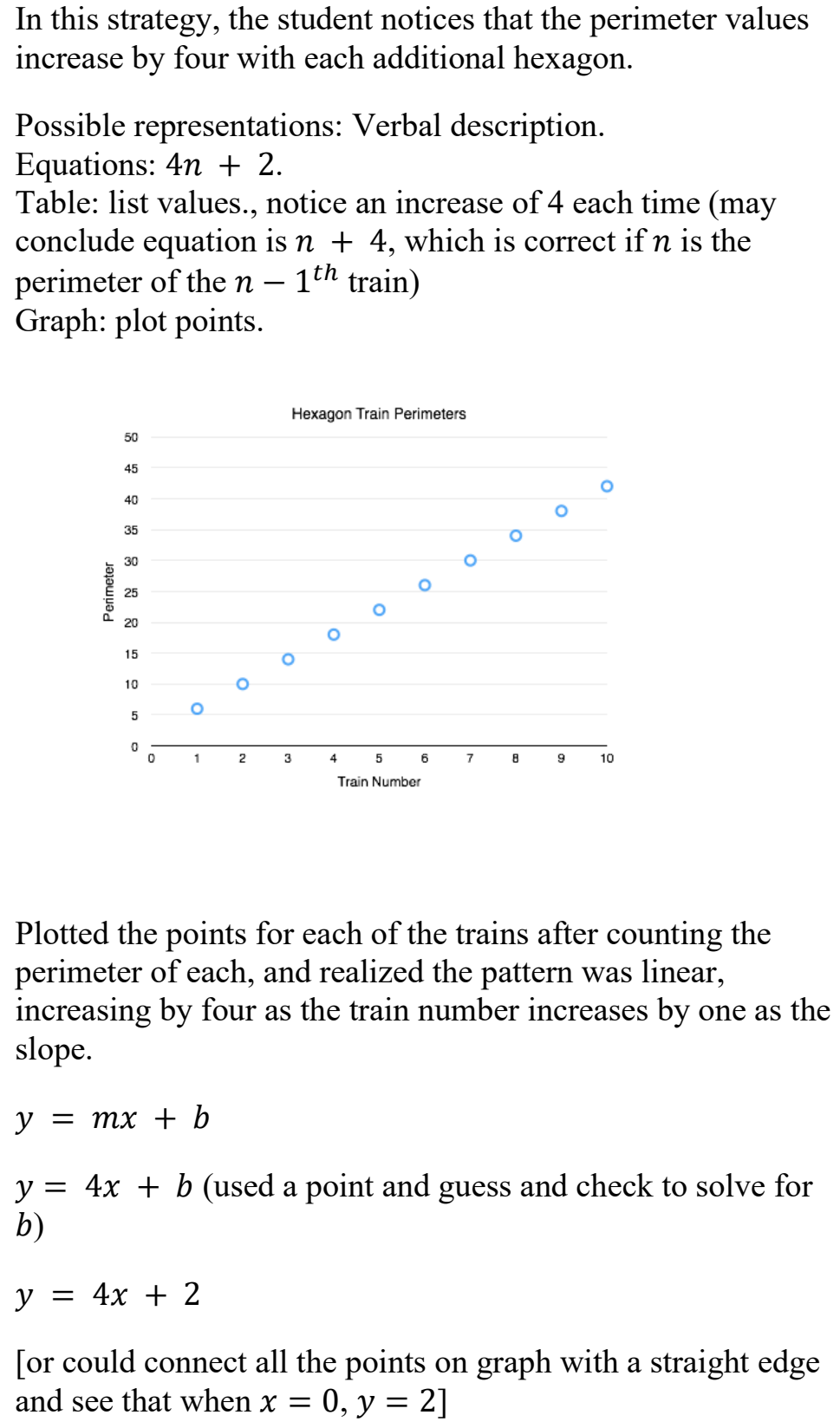 \\
\hline
\end{tabular}


Task 3b: Explain Multiple Solution Strategies

\begin{tabular}{|c|c|c|}
\hline Topic & Component & Description of Coding \\
\hline \multirow{4}{*}{$\begin{array}{l}\text { Finding the } \\
\text { pattern in the } \\
\text { Hexagon task }\end{array}$} & $\begin{array}{l}\text { Explains } \\
\text { procedurally } \\
\text { what students } \\
\text { might have done }\end{array}$ & $\begin{array}{l}\text { - Explains how students get each solution pattern. } \\
\text { For Rachel's response, indicates that } 2 n+2 n+2 \text { or } \\
2(2 n)+2 \text { can be found by adding tops and bottoms plus } \\
\text { ends. }\end{array}$ \\
\hline & & $\begin{array}{l}\text { For Sam's response, indicates that } 5+4(n-2)+5 \text {, or } \\
4(n-2)+5+5 \text {, or } 4(n-2)+10 \\
\text { can be found by adding the insides and outsides. }\end{array}$ \\
\hline & & $\begin{array}{l}\text { For Jason's response, indicates that } 6 n-2(n-1) \text { can be } \\
\text { found by adding all sides minus shared sides. }\end{array}$ \\
\hline & $\begin{array}{l}\text { Explains } \\
\text { conceptually } \\
\text { what students } \\
\text { might have done }\end{array}$ & $\begin{array}{l}\text { - Indicates that there is a pattern between the number of } \\
\text { train and the perimeter of the hexagons. } \\
\text { - Indicates that the pattern consists of both multiplying (by } \\
\text { 4) and adding (by 2). }\end{array}$ \\
\hline
\end{tabular}


Scoring Rubric for the Counting Cubes task

\begin{tabular}{|c|c|c|c|}
\hline \multicolumn{4}{|c|}{ Task 2: Generate Multiple Solution Strategies } \\
\hline Topic & Valid Strategies & \multicolumn{2}{|c|}{ Description of Coding } \\
\hline \multirow{9}{*}{$\begin{array}{l}\text { Finding the } \\
\text { pattern in the } \\
\text { Counting Cubes } \\
\text { task }\end{array}$} & Arms plus middle cube & \multicolumn{2}{|c|}{$\begin{array}{l}\text { In this strategy, the student considers that the } \\
\text { figure has } 5 \text { arms and the number of cubes in } \\
\text { each arm is } 1 \text { less than the number of building } \\
\text { number. } \\
\qquad 1+5(n-1)=1+5 n-5=5 n-4\end{array}$} \\
\hline & Arms minus 4 cubes & \multicolumn{2}{|c|}{$\begin{array}{l}\text { In this strategy, the student considers that the } \\
\text { figure has } 5 \text { arms and the number of cubes in } \\
\text { each arm is the same as the building number. } \\
\text { Then, students subtract } 4 \text { cubes since in the } \\
\text { pattern, there is } 1 \text { cube less in each arm. } \\
5 n-4\end{array}$} \\
\hline & Arms plus tower & \multicolumn{2}{|c|}{$\begin{array}{l}\text { In this strategy, the student considers that there } \\
\text { is one tower in the middle and } 4 \text { arms in the } \\
\text { figure. The tower has } n \text { cubes ( } n \text { : building } \\
\text { number) and each arm has } n-1 \text { cubes. } \\
\qquad n+4(n-1)=n+4 n-4=5 n-4\end{array}$} \\
\hline & \multirow[t]{6}{*}{ Table method } & \multicolumn{2}{|l|}{ Table method: } \\
\hline & & $\begin{array}{c}\text { Building } \\
\text { number }\end{array}$ & Number of Cubes \\
\hline & & 1 & 1 \\
\hline & & 2 & $1+5=6$ \\
\hline & & 3 & $1+5+5=11$ \\
\hline & & \multicolumn{2}{|c|}{$\begin{array}{l}\text { By using the table, students find the number of } \\
\text { cubes as the following ( } n \text { is the building } \\
\text { number) } \\
1+5(n-1)=5 n-4\end{array}$} \\
\hline
\end{tabular}


Task 3b: Explain Multiple Solution Strategies

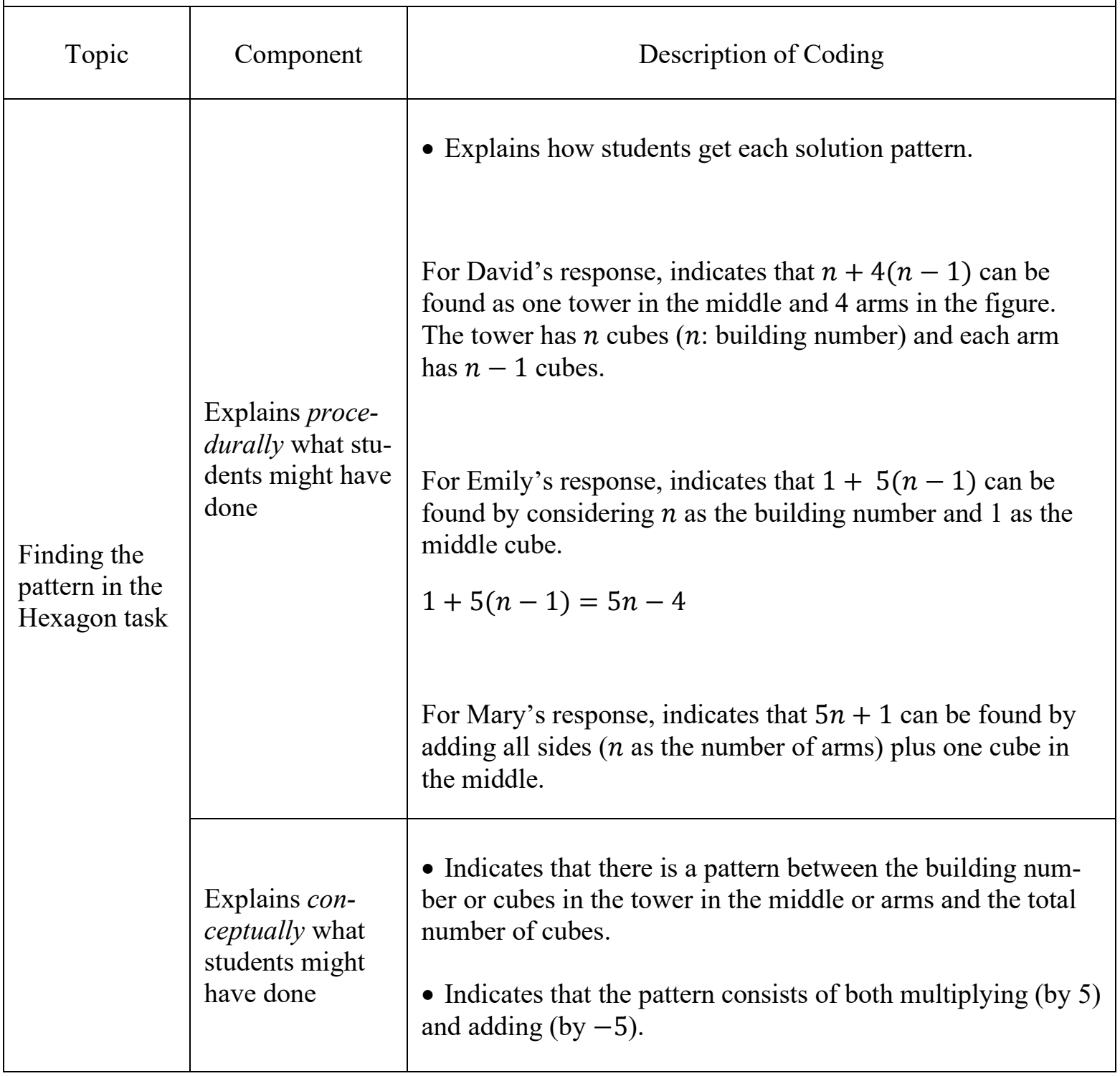


Scoring Rubric for the Two Storage Tanks task

\begin{tabular}{|c|c|c|c|}
\hline \multicolumn{4}{|c|}{ Task 1: Identify Concepts Underlying Procedures } \\
\hline Topic & Concept & Score & Description of Coding \\
\hline \multirow{9}{*}{ Two Storage Tanks Task } & \multirow{3}{*}{$\begin{array}{l}\text { Linear } \\
\text { Equations } \\
\text { in two } \\
\text { variables }\end{array}$} & 0 & $\begin{array}{l}\text { - Makes no mention of the linear } \\
\text { equations. }\end{array}$ \\
\hline & & 1 & $\begin{array}{l}\text { - Makes a general statement that } \\
\text { students should consider that the } \\
\text { graphs are linear and there are two } \\
\text { variables ( } x \text { : number of hours, } y \text { : } \\
\text { galloons of water) }\end{array}$ \\
\hline & & 2 & $\begin{array}{l}\text { - Sees that there is a linear } \\
\text { relationship between variables } x \\
\text { and } y \text { variables. Provides further } \\
\text { explanations on what } x \text { and } y \text { refers } \\
\text { to and gives specific examples by } \\
\text { using the graph provided in the task. }\end{array}$ \\
\hline & \multirow{3}{*}{$\begin{array}{l}\text { Initial } \\
\text { Value of } \\
\text { the } \\
\text { function }\end{array}$} & 0 & $\begin{array}{l}\text { - Makes no mention of the initial } \\
\text { value of the function. }\end{array}$ \\
\hline & & 1 & $\begin{array}{l}\text { - Makes a general statement that } \\
\text { students should consider the initial } \\
\text { value of the function for finding the } \\
\text { intersection point of two equations. }\end{array}$ \\
\hline & & 2 & $\begin{array}{l}\text { - Sees how the initial value might } \\
\text { impact the intersection point and } \\
\text { provides further explanations by } \\
\text { giving specific numbers from the } \\
\text { given graph. }\end{array}$ \\
\hline & \multirow[b]{3}{*}{$\begin{array}{l}\text { The rate of } \\
\text { change }\end{array}$} & 0 & $\begin{array}{l}\text { - Makes no mention of the rate of } \\
\text { change. }\end{array}$ \\
\hline & & 1 & $\begin{array}{l}\text { - Makes a general statement that the } \\
\text { rate of change impact the } \\
\text { intersection point of two linear } \\
\text { equations. }\end{array}$ \\
\hline & & 2 & $\begin{array}{l}\text { - Sees that the rate of change is the } \\
\text { slope of the function and how } \\
\text { different rate of changes might } \\
\text { impact on the intersection point. } \\
\text { - Provides examples on how small } \\
\text { or big rate of change might impact } \\
\text { the steepness of the graph and what } \\
\text { it means to be steeper by comparing } \\
\text { different rates of change. }\end{array}$ \\
\hline
\end{tabular}

